\title{
ARTIFICIAL INTELLIGENCE AND LEARNING ACTIVITIES: A MATCH MADE IN HEAVEN?
}

Henrik Køhler Simonsen, Copenhagen Business School, Denmark, José Manuel Emiliano Bidarra de Almeida, Universidade Aberta, Portugal

\section{Abstract}

Artificial Intelligence in Education (AIED) may be described as the next big disruptor in higher education, however, AIED still only remains "evidence of a potential" Balslev (2020). Practical experience with AI in higher education is very limited and potential pedagogical applications of AI has so far not been given much attention. The objective of this paper is to analyse and discuss concrete applications of AI to support different learning activities in higher education using the ABC Learning Design approach Young and Perovic (2016). The purpose of the paper is to contribute to research in the practical use of AI in higher education by presenting the AI Pedagogy Planner and to start the important theoretical discussion of AI applications from a pedagogical point of view. The paper is based on empirical data from nine selected cases of AI use in higher education in Portugal, the United Kingdom and Denmark, respectively. The analysis demonstrated that there is a need for new views on the pedagogical use of $\mathrm{AI}$ in higher education. However, the paper goes further and outlines an AI Pedagogy Planner combining six overall learning activities with eight types of AI applications.

Keywords: AIED, learning types, AI applications, AI pedagogy planner

\section{Introduction}

The purpose of this paper is to analyse and discuss pedagogical applications of artificial intelligence in higher education and to answer the overall question: which AI applications support specific learning activities in higher education?

The study draws on empirical insights from a structured analysis of nine different cases, describing nine AI applications in higher education in Portugal, the United Kingdom and Denmark, respectively. The analysis of the nine cases focused on particular parameters 
that are relevant for pedagogical and/or didactical factors related to the actual use of AI in Education.

In a recent article offering a systematic review of research on artificial intelligence applications in higher education, Zawacki-Richter et al. (2019) ask a crucial question. Based on their comprehensive systematic review they ask: "where are the educators?"

This question has been raised before by Holmes et al. (2019) and in other variants by Rienties et al. (2020) and Simonsen (2020), and it is definitely about time that we discuss potential pedagogical approaches to artificial intelligence applications in higher education. The analysis of the nine cases used in this paper are related to the question raised. We will try to answer that question and offer a theoretically based discussion of how elements from the ABC Learning Design Approach Young and Perovic (2016) can be combined with an emerging framework outlining potential applications of different AI technologies, based on the three-tier classification developed by Luckin et al. (2016) and Holmes (2019).

So, the paper will first briefly introduce and discuss the different theoretical building blocks. Then it will provide an analysis and discussion of the nine cases and suggest an AI Pedagogy Planner, which may help educators select the right kind of AI application to support specific learning types. Finally, conclusions and reflections on further work will be presented.

\section{Al Applications and Pedagogy in Higher Education}

As already indicated, existing literature does not fully discuss the link between AI applications and potential learning activities in higher education. Holmes et al. (2019) do discuss how AI works in education and how different AI applications work in education, but they do not propose an overall pedagogical framework of which type of AI application can be used to support specific learning activities. Zawacki-Richter et al. (2019) even ask, "where are the educators?" and the educators have so far played an almost non-existing role in the development of AI applications for higher education.

That is unfortunate because we might miss the huge potential of AI applications without a clear pedagogical approach. Also Rienties et al. (2020) call for increased cooperation between different disciplines to gain the full potential, and Simonsen (2020) points out that we have not come very far when it comes to the actual practical use of AI in higher education. In a more critical view, Balslev (2020) criticises the application of technology and $\mathrm{AI}$ in higher education and calls it "Evidence of a potential".

In other words, there seems to be a need for a specific approach to AI pedagogy, which focuses not only on what AI can do, but also on which learning activities and learning objectives can be supported by AI applications. That is the conceptual vision of this paper. 
However, it needs some solid theoretical building blocks and, for that purpose, the framework presented in Holmes et al. (2019), and later refined and expanded in Bidarra et al. (2020) should be presented.

The overall classification of learning and artificial intelligence suggests three overall types of AI in education. The classification is important as it divides the overall uses of AI in education into three areas being Learning with AI, Learning about AI and Learning for AI.

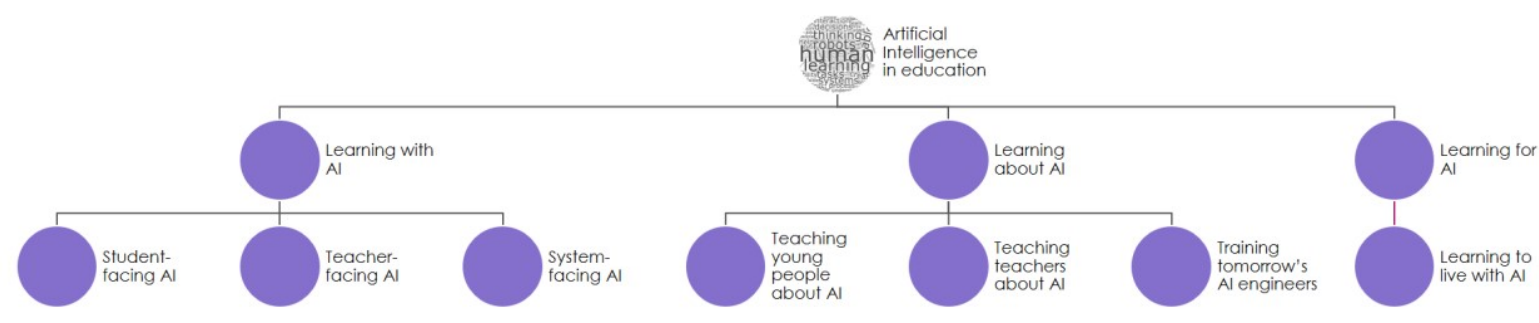

Figure 1. Learning with $\mathrm{Al}$, learning about $\mathrm{Al}$ and learning for $\mathrm{Al}$

This overall classification is useful when defining what type of learning we are aiming at, and as such the three categories form the basis of the AI Pedagogy Planner, which will be presented later.

The next theoretical building block is the emerging framework outlining existing AIED technologies based on Holmes et al. (2019). This approach has been updated and streamlined by Bidarra et al. (2020) and is shown below in Figure 2.

The upper section of Figure 2 outlines whether the solution in question supports learning with AI, learning about AI or learning for AI and the lower section outlines a nonexhaustive list of different AI applications, cf. Holmes et al. (2019).

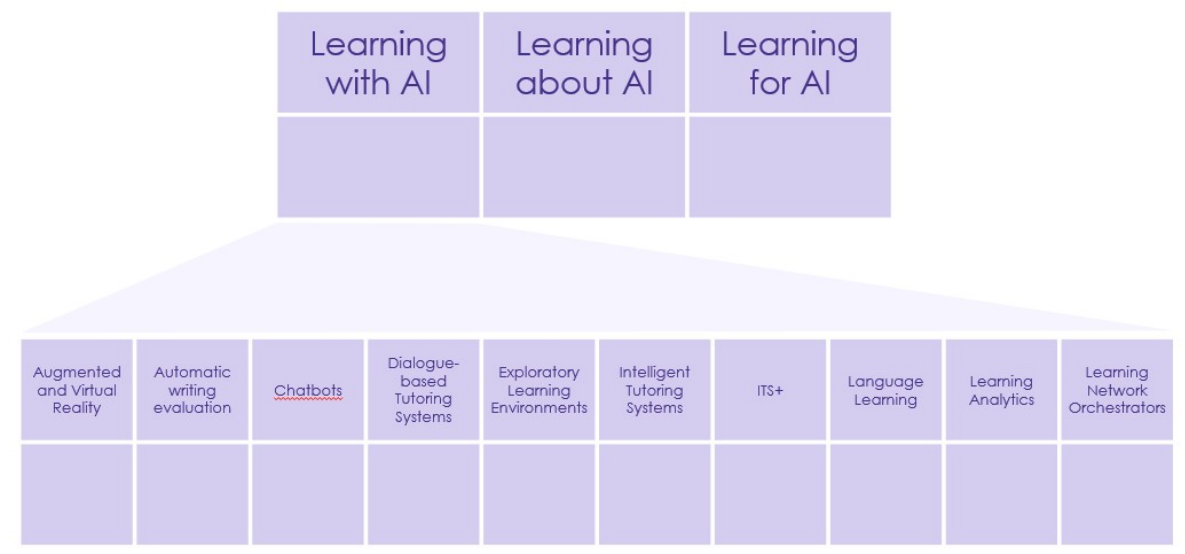

Figure 2. Framework of Al learning types and AIED technologies

These two theoretical building blocks make it possible to categorize the overall purpose of an AI application and to present an overall description of the AI solution in question. 
However, we still miss a recognized pedagogical approach that allows us to describe systematically what AI applications to use when supporting specific learning activities and reaching specific learning objectives. We need the third theoretical building block.

For that purpose, we selected elements from the ABC Learning Design method Young and Perovic (2016), which builds on Laurillard's six learning types Laurillard (2012). The ABC Learning Design approach is a method where educators work together in teams to design a visual storyboard outlining the structures and sequences of learning activities, which are required to meet specified learning outcomes.

For this discussion, only the overall learning types are used. The six learning types outlined in the ABC Learning Design method Young and Perovic (2016) include:

- Acquisition;

- Collaboration;

- Discussion;

- Investigation;

- Practice;

- Production.

The definitions of each learning type can be found in Young and Perovic (2016) and are written on the actual cards used in the ABC Learning Design method.

These three building blocks constitute the theoretical basis of this paper and before we turn our attention to the AI Pedagogy Planner, we need to take a look at the nine cases that form the empirical basis of this paper.

\section{Nine Cases on Al in Higher Education}

One of the research objectives of the AI in Teaching project (AIT) supported by ERASMUS+ (KA203-2019-002) was to identify and analyse cases in Portugal, the United Kingdom and Denmark, respectively.

The AIT group has identified nine cases, which are listed by country and shown below in Figure 3. 


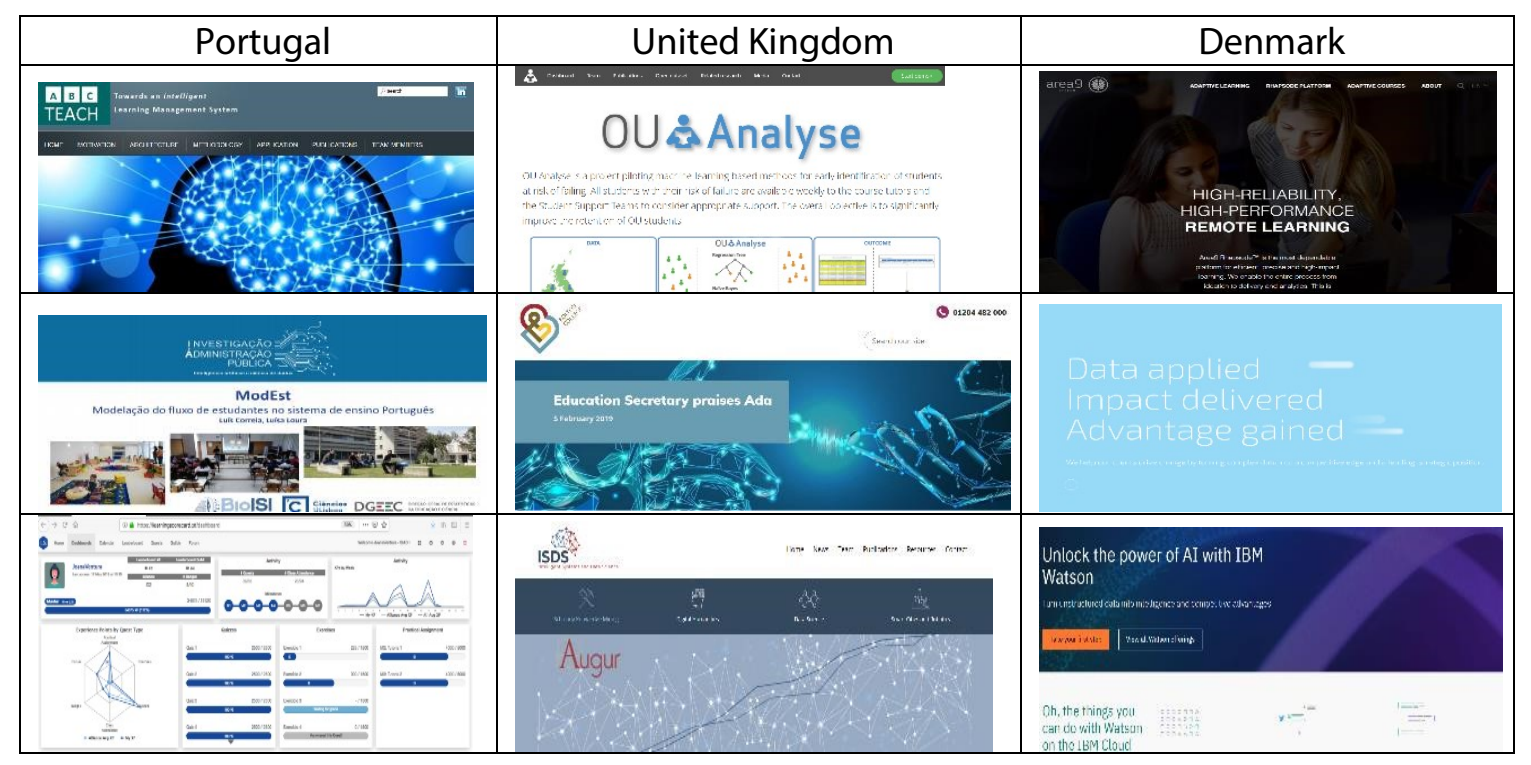

Figure 3. Screenshots of the nine cases

All nine cases were found in higher education and were analysed on the basis of the following items:

- Context;

- Description of AI application;

- Categorization of AI application;

- Actors (Students-Teachers-Researchers-Decision-makers);

- Conclusion.

Based on this study it was possible to analyse the nine cases and categorize them by AI learning type and AI applications. Figure 4 below shows the nine cases categorized using first the AI learning types and secondly the AI application types.

\begin{tabular}{|c|c|c|c|c|c|c|c|c|c|}
\hline & ABCTeach & ModEst & LearningScorecard & OUAnalyse & ADA-Chatbot & KMI & Area9 & SDU & DKEA \\
\hline \multicolumn{10}{|l|}{ Al Learning Types } \\
\hline Learning With Al & $x$ & $x$ & $x$ & $x$ & $x$ & $\mathrm{x}$ & $x$ & $\mathrm{x}$ & $x$ \\
\hline \multicolumn{10}{|l|}{ Learning About Al } \\
\hline \multicolumn{10}{|l|}{ Learning For Al } \\
\hline \multicolumn{10}{|l|}{ Al Applications } \\
\hline \multicolumn{10}{|l|}{ Automatic Writing Evaluation } \\
\hline Chatbots & & & & & $x$ & & & & \\
\hline \multicolumn{10}{|c|}{ Dialogue-based Tutoring Systems } \\
\hline \multicolumn{10}{|c|}{ Exploratory Learning Environments } \\
\hline Intelligent Tutoring Systems & $x$ & $x$ & $x$ & & & & $x$ & & $x$ \\
\hline \multicolumn{10}{|l|}{ Language Learning } \\
\hline Learning Analytics & & & & $x$ & & $x$ & & $\mathrm{x}$ & \\
\hline AugmentedNirtual Reality & & & & & & & & & \\
\hline
\end{tabular}

Figure 4. Categorization of the nine cases

The results show that all nine cases are under the learning with AI category, and that there was 1 chatbot application, 3 learning analytics applications and 5 intelligent tutoring system applications. Furthermore, the analysis showed that none of the nine cases was based on pedagogical considerations, which was a finding, which supports the call for 
Køhler Simonsen, H., \& Bidarra de Almeida, J. M. E.

Artificial Intelligence and Learning Activities: A Match Made in Heaven?

including educators in AIED development, cf. Zawacki-Richter et al. (2019). Although the sample is small, it points to a need for combining pedagogical considerations with AI.

\section{Al Pedagogy Planner}

The idea of using a design approach in building programmes has had a huge impact on educators and researchers all over the world, and in this case, inspiration to develop the AI Pedagogy Planner came from Bower (2008), Laurillard (2012), Salmon (2013) and Fung (2015). Let us first outline how the ABC Learning Design method works.

The actual process used in the ABC Learning Design method is based on a practical and hands-on approach where educators are asked to develop a programme using a storyboard and cards. The storyboard structures the programme in question in a timeline, and the cards are placed in the desired sequence to support the learning objectives in question. On the front of the learning type card the overall type of learning appears and the educator places several learning type cards on the storyboard, structuring the overall learning programme. All these choices are of course made to support the learning objectives of the programme. Once satisfied with the overall approach, educators then flip the learning type cards and select or define the actual learning activities on the back of the card in question. Having gone through this process all pedagogically relevant choices have been made and educators can now start developing the specific didactical activities in the classroom or the LMS in question. The same idea was used to develop the AI Pedagogy Planner, which is shown in Figure 5 below.

Again, the underlying idea was to develop a practical tool for educators when working with $\mathrm{AI}$ in higher education. In line with the ABC Learning Design method, the idea is to make pedagogically relevant decisions in a specific sequence.

The AI Pedagogy Planner is a so-called decision support tool, where you start with the inner white wheel. First, you select the type of learning that you want to work with at a particular stage in your curriculum design by turning the inner wheel either left or right. The abbreviations ACQ, COL, DIS, INV, PRA, and PRO are the six learning types listed in the left-hand side of Figure 5.

Having selected the learning type, then it is time to select the AI learning types, cf. Holmes et al. (2019) and Bidarra et al. (2020). The educator now selects the AI learning type in question, that is, whether it is Learning with AI, Learning about AI or Learning for AI by turning the second light-grey wheel. The abbreviations LWAI, LAAI and LFAI are the three AI learning types listed in the left-hand side of Figure 5. 
Next, it is time to select the actual AI application, which the educator can use to realize the didactical learning activities required. The educator now turns the outer dark grey wheel and selects the AI application(s), which support(s) the selected learning type in question.

Once the learning type, the AI learning type and the equivalent AI applications have been selected, the educator flips the decision tool and gets concrete pointers to actual exercises, practical learning activities and AI tools that may be used to realize the learning outcomes of the programme in question on the back of the AI Pedagogy Planner. The abbreviations AWE, CB, DBTS, ELE, ITS, LL, LA and AR/VR are abbreviations of different AI applications listed in the left-hand side of Figure 5.
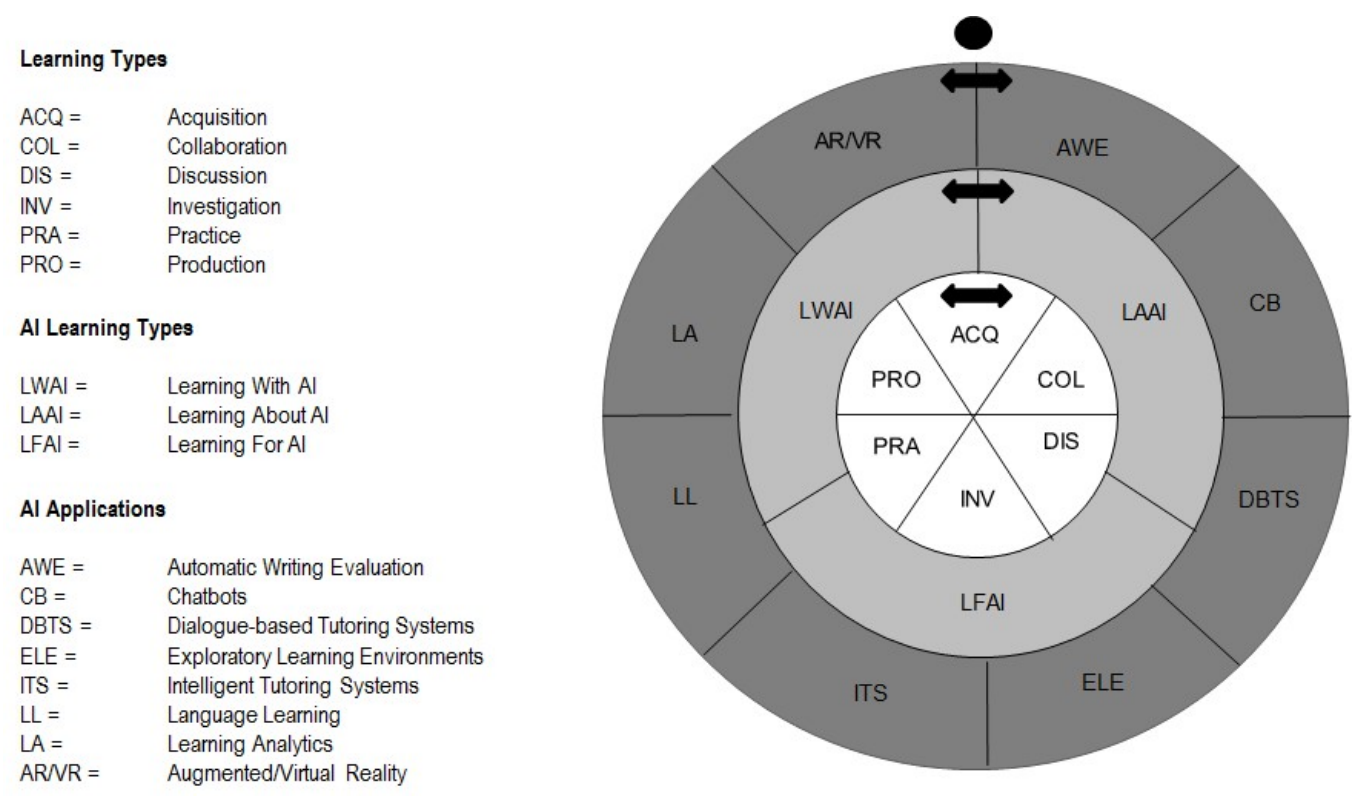

Figure 5. Al Pedagogy Planner

\section{Conclusions and further work}

This paper analysed and discussed pedagogical applications of artificial intelligence in higher education and examined how AI applications may support specific learning activities in higher education. The discussion was based on nine cases of AI applications in Portugal, the United Kingdom and Denmark, respectively and the insights gained from the study led to the development of the decision support tool called the AI Pedagogy Planner. We argue that this specific decision support tool may help educators select the right $\mathrm{AI}$ applications for the right learning types realizing the right learning activities.

During the analysis of the nine cases, it was found that all nine cases could be categorized as learning with AI and that five out of eight AI applications were categorized as intelligent tutoring systems. It was also found that none of the nine cases included detailed theoretical considerations on how the solutions in question could be used pedagogically. We contend that the decision support tool based on a picker wheel approach to AIED could be used in 
practice by educators to facilitate pedagogically based decisions in the process of building the curriculum in higher education. Artificial Intelligence and learning activities are in fact a match made in heaven, but educators should lead AI - not be led by AI.

Consequently, further research in pedagogically based development of AI applications is needed to be able to integrate them in the physical classroom or in the virtual learning environment, cf. Luckin and Holmes (2017).

\section{References}

Balslev, J. (2020). Evidence of a potential. The political arguments for digitizing education 1983-2015 (Doctoral dissertation). Roskilde University, Roskilde.

Bidarra, J., Holmes, W., \& Køhler Simonsen, H. (2020). Artificial Intelligence in Teaching (AIT): A road map for future developments. Paper presented at Empower EADTU, Webinar week: Artificial Intelligence in Online Education. Retrieved September 5, 2020, from https://www.slideshare.net/EADTU/ait-empower-by-jos-bidarra-wayneholmes-and-henrik-kohler-simonsen

Bower, M. (2008). Affordance analysis - matching learning tasks with learning technologies, Educational Media International, 45(1), 3-15. doi:10.1080/09523980701847115

Fung, D. (2015). A Connected Curriculum for Higher Education. UCL Press: London. Retrieved from https://discovery.ucl.ac.uk/id/eprint/1558776/

Holmes, W. (2019). Artificial Intelligence in Education Promise and Implications for Teaching and Learning. Paper presented at the ICOME2019 Conference.

Holmes, W., Bialik, M., \& Fadel, C. (2019). Artificial Intelligence in Education: Promises and implications for teaching and learning. Boston, MA: Center for Curriculum Redesign.

Laurillard, D. (2012). Teaching as a Design Science: Building Pedagogical Patterns for Learning and Technology. New York and London: Routledge.

Luckin, R., \& Holmes, W. (2017, January 7). A.I. is the New T.A. in the Classroom. How We Get to Next [blog post]. Retrieved May 14, 2020, from https://howwegettonext.com/a-iis-the-new-t-a-in-the-classroom-dedbe5b99e9e\#---0237.wcmt24rx7

Luckin, R., Holmes, W., Griffiths, M., \& Forcier, L. B. (2016). Intelligence Unleashed: An argument for AI in Education. London, Pearson. 
Rienties, B., Simonsen, H. K., \& Herodotou, C. (2020) Defining the Boundaries between Artificial Intelligence in Education, Computer-Supported Collaborative Learning, Educational Data Mining, and Learning Analytics: A Need for Coherence. Frontiers in Education, 5(128). doi: 10.3389/feduc.2020.00128

Salmon, G. (2013). E-tivities: The Key to Active Online Learning. New York: Routledge.

Simonsen, H. K. (2020): AI i uddannelsessektoren - hvor langt er vi? In H. Køhler Simonsen (Ed.), Forsøg med uddannelsesdigitalisering og uddannelsesformater (pp. 5158). Samfundslitteratur ISBN: 978-87-7209-369-7.

Young, C., \& Perovic, N. (2016). Rapid and Creative Course Design: As Easy as ABC? Procedia - Social and Behavioral Sciences, 228, 390-395.

Zawacki-Richter, O., Marín, V. I., Bond, M., \&Gouverneur, F. (2019). Systematic review of research on artificial intelligence applications in higher education - where are the educators? International Journal of Educational Technology in Higher Education, 16(1), 1-27.

\section{Acknowledgements}

This paper has received funding through ERASMUS+ (KA203-2019-002) and is a knowledge dissemination activity by the AI in Teaching project (AIT). 